\title{
LABORATORY BIODEGRADATION OF POTENTIAL CELLULOSE WASTES GENERATED DURING LONG-TERM MANNED SPACE MISSIONS
}

\author{
Najdenski H. ${ }^{1}$, V. Ilyin ${ }^{2}$, P. Angelov³, V. Hubenov ${ }^{1}$, D. Korshunov ${ }^{2}$, \\ V. Kussovski ${ }^{1}$, L. Dimitrova ${ }^{1}$, I. Simeonov ${ }^{1}$ \\ ${ }^{1}$ The Stephan Angeloff Institute of Microbiology, Bulgarian Academy of Sciences \\ ${ }^{2}$ Russian Federation State Scientific Center - Institute for Biomedical Problems, Russian Academy of Sciences \\ ${ }^{3}$ Space Research and Technology Institute, Bulgarian Academy of Sciences
}

\begin{abstract}
Anaerobic microbial biodegradation of cellulose containing wastes generated during the long-term manned space missions is a key technological approach for resolving the problem of wastes accumulated onboard of the spacecraft. Herewith are presented data on the possibilities of structurally stable multispecies microbial consortia originating from methanogenic bioreactors to decompose different cellulose substrates - filter paper, medical gauze and vegetable mix as potential cellulose wastes during space missions. The rates of biodegradation processes carried out at mesophilic and thermophilic conditions are not only measured and compared but are providing new opportunities for development of technology for microbial biodegradation of cellulose-rich organic wastes. Moreover, the studies have shown that paper and gauze hydrolysis with the help of cellulolytic bacterial communities can be an effective component of utilization of cosmonaut hygiene items. Biodegradation of plant wastes by community of anaerobic bacteria is promising and applicable tool also under terrestrial conditions. Light microscopy of bacterial communities reveals the presence of Gram-positive spore forming bacilli (short and long forms, bipolar and dividing cells) and typical clostridia forms.
\end{abstract}

Keywords: cellulose containing wastes, biodegradation, anaerobic digestion, bacterial consortia, long-term manned space missions

\section{INTRODUCTION}

Planned in the near future, space flight to Mars and others long-term manned space missions raise a number of impressive issues for modern science. One of the most important item is how to dispose of crew organic waste during space mission. The relative proximity of the Earth allows the waste from the International Space Station (ISS) to be removed through the container and burst into the atmosphere. During the expedition to Mars or Moon for example, it will be impossible since this garbage cannot be thrown into space and this requires its recycling. Investigations on this problem are conducted intensively in the leading space countries in the world. An international group of experts is working on the creation of a closed ecosystem in the framework of MELiSSA project at the European Space Agency [Lasseur et al., 2006; Hendrickx et al., 2010]. In the frame of the project, organic waste are disposed of different groups of bacteria in special bioreactors. The goal is to get water from the disposal of this waste, which will be used for the space greenhouse, or some kind of gas that would serve as a source of energy. Scientists will investigate the behavior of terrestrial bacteria in microgravity on the ISS.

Investigations on the ability of microorganisms for waste utilization in space conditions date back to the first piloted spaceflights. The variety of microorganisms used for research at such conditions is considerable. This includes: viruses, bacteria, fungi [Benot and Klaus, 2005; Taylor et al., 1975]. For example, the main microorganisms tested on board of the spacecraft "Apollo 16" and the satellite "Biokosmos 2044" were representatives of the species: Bacillus subtilis, Aeromonas proteolytica, Bacillus thuringiensis, Escherichia coli, and the fungus Trichosporon terrestre, Saccharomyces cerevisiae, Rhodotorula rubra [Bouloc and D'Ari, 1991; Taylor et al., 1975]. American researchers [Chynoweth et al., 2006.] have conducted anaerobic digestion of organic wastes (domestic, agricultural, paper, etc.) under the ground gravitation conditions. They have created a variant of their earlier patented apparatus [Chynoweth and Legrand, 1993] to operate on board the spacecraft, i.e. in microgravity.

Different cellulosic wastes like hygienic materials, food refuse, paper, cotton, clothing, wipes, grey tapes etc. show different potential for biodegradability due to their specific lignocelluloses structure [Pullammanappallil and Dhoble, 2010]. The general structure of lignocelluloses from plant cell walls for example, contains a mixture of polysaccharides of high molecular weight. The major components are cellulose, hemicellulose, and lignin. Cellulose is a structural polymer of glucose residues joined by $\beta-1,4$ linkages. 


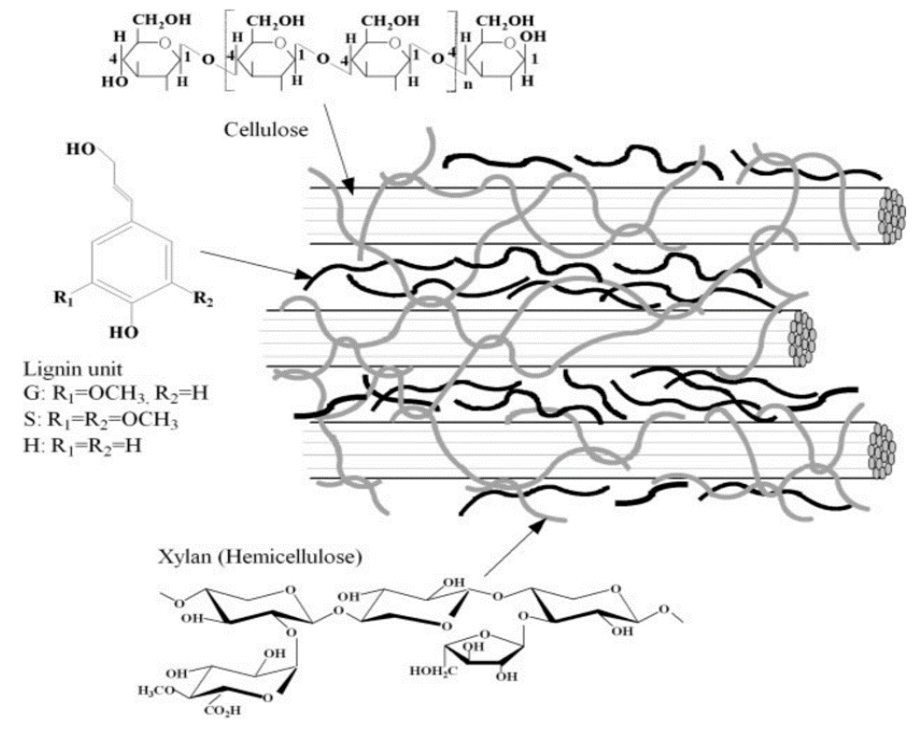

Figure 1. Schematic structure of lignocellulose [Wang et al., 2013].

Glucose, which could be produced by the hydrolysis of cellulose, can also proceed enzymatically under the action of cellulase, which degrades it to cellobiose disaccharide and by cellobiase enzyme this saccharide is hydrolyzed to glucose. The cellulose is biochemically degrading by specific anaerobic bacteria to fatty acid, acetic acid, ethanol, $\mathrm{CO}_{2}$ and $\mathrm{H}_{2}$. This process is called cellulose fermentation. For example, the dark cellulose fermentation by Caldicellulosiruptor saccharolyticus is based on the following formula:

$$
\mathrm{C}_{6} \mathrm{H}_{12} \mathrm{O}_{6}+2 \mathrm{H}_{2} \mathrm{O} \rightarrow 4 \mathrm{H}_{2}+2 \mathrm{CO}_{2}+2 \mathrm{CH}_{3} \mathrm{COOH}
$$

The $\mathrm{H}_{2}$ is universal energy carrier, which can be used as a source of light energy in greenhouse by hydrogen fuel cells, which are environmentally clean and highly technological effective. The $\mathrm{CO}_{2}$ can be used in the photosynthesis and to obtain oxygen, which is a life-supporting for the crews of the spacecraft, by the following formula:

$$
6 \mathrm{H}_{2} \mathrm{O}+6 \mathrm{CO}_{2}+\text { sunlight }=\mathrm{C}_{6} \mathrm{H}_{12} \mathrm{O}_{6}+6 \mathrm{O}_{2}
$$

It is known that aerobic bacteria produce numerous individual, extra-cellular enzymes with binding modules for different cellulose conformations. Specific enzymes act in synergy to elicit effective hydrolysis. In contrast, anaerobic bacteria possess a unique extracellular multi-enzyme complex, called cellulosome [Schwarz W.,2001]. The exact composition of the cellulosomes depend on growth rate and the nature of substrates available. The most complex and best investigated cellulosome is that of the thermophilic bacterium Clostridium thermocellum, but a scheme for the cellulosomes of the mesophilic clostridia and the ruminococci emerges. Many crucial details of cellulose hydrolysis are still to be uncovered [Schwarz W., 2001].

Among the wastes that are formed in the conditions of manned space flight, a significant proportion is spent on personal hygiene (medical gauze). The greenhouses for the reproduction of the vegetative part of the diet of cosmonauts are considered as a necessary element of the closed Life Support System (LSS) of manned spacecraft. Uneaten parts of plants suggested for growth in space like wheat, rice, lettuce, radishes, carrots, mushrooms etc. form the waste from greenhouses. Used and accumulated personal hygiene products and greenhouse waste will occupy significant volumes, which will lead to an increase in the equivalent weight of the system [Berkovich, 2005; Jones, 2006].

One of the natural ways of recycling waste is their microbial degradation. In general, microbial degradation is an artificial intensification of mineralization processes in natural biocenoses. For example for the hydrolysis of cellulose-containing materials it is advisable to use anaerobic microorganisms that have a number of important advantages: 1) cellulolytic anaerobes, as well as other fermenting anaerobic microorganisms, have a slight biomass gain - most of the substrate is transformed into various end products such as ethanol, organic acids, $\mathrm{CO}_{2}, \mathrm{H}_{2}$, etc. [Bilai, 1986], which are easier to dispose later than microbial biomass; 2) they have a high specific cellulolytic activity, which depends little on the nature of the substrate; 3) they have relatively high growth rates 
on cellulose-containing substrates [Loginova et al., 1988]. At present, one of the constantly accumulating types of waste generated onboard the spacecraft are hygienic gauze wipes, which has to be regularly returned from the ISS to the Earth. Ilyin et al. [2018] proposed as one of the most effective ways to reduce their quantity by degradation with anaerobic microorganisms.

One of the significant problems in the way of anaerobic degradation of solid organic waste is that liquid fermentation products contain a significant amount of organic impurities, which often give them a low $\mathrm{pH}$. This circumstance does not allow to use the received liquids as technical water or in any other way without additional processing. It should be noted that the accumulation of liquid organic waste originating from plant residues is also a problem in agriculture, where only $10 \%$ of these substrates are somehow disposed of [Ilyin et al., 2018].

The aim of the present work is to study the process of laboratory biodegradation of filter paper and medical gauze as potential hygienic cellulose wastes onboard of the spacecraft as well as the plant wastes generated in the space greenhouses.

\section{MATERIALS AND METHODS}

\section{Isolation of cellulolytic bacterial consortium from methanogenic bioreactors}

The methanogenic bioreactor (BR1, 21 working volume) started with cow manure in periodic mode of exploitation and mesophilic conditions $\left(37^{\circ} \mathrm{C}\right)$. Practically, the bioreactor starts with $40 \mathrm{~g} / \mathrm{l}$ of cow manure. After 15 days, $3.5 \mathrm{~g} / \mathrm{l}$ of powdered filter paper was added and after 11 days an additional 5.0 $\mathrm{g} / \mathrm{l}$ was added. After 21 days, the bioreactor was again loaded with $5.0 \mathrm{~g} / \mathrm{l}$ of powdered filter paper and a further $7.5 \mathrm{~g} / \mathrm{l}$ was added after 21 days. On day 52 , a liquid sample was taken to inoculate the tubes containing different cellulose substrates in concentration $20 \%(\mathrm{v} / \mathrm{v})$. The second bioreactor (BR2) was loaded with the same compounds but was working at thermophilic regime $\left(55^{\circ} \mathrm{C}\right)$ and served as a source for thermophilic bacterial inoculum. The powdered filter paper was prepared by cutting of filter paper into strips and soaking in concentrated $\mathrm{HCl}$ for $24 \mathrm{~h}$. The mixture was then filtered and washed with distilled water $\left(\mathrm{dH}_{2} \mathrm{O}\right)$ to neutral $\mathrm{pH}$ value of the wash waters. Afterwards, the paper was dried and grind to powder.

\section{Nutrient media and cellulose substrates}

The first group of experiments was performed in glass tubes with nutrient media for Ruminiclostridium cellulolyticum (CM3) 520 DSMZ and for Hungateiclostridium thermocellum - Hungateiclostridium 122 DSMZ, in which cellobiose was replaced by pre-cut Whatman filter paper or sterile medical gauze in quantity of $10 \mathrm{mg} / \mathrm{ml}$. The media were inoculated with $20 \%(\mathrm{v} / \mathrm{v})$ supernatant liquid from the respective bioreactor as a source of bacterial biomass. Due to the high content of $\mathrm{H}_{2} \mathrm{~S}$ in the separated gas mixture during the experiments, $\left(\mathrm{NH}_{4}\right)_{2} \mathrm{SO}_{4}$ was replaced by $\mathrm{NH}_{4} \mathrm{Cl}$. Others applied nutrient media involved: Carboxymethylcellulose (CMC) agar, peptone cellulose solution (PCS) with $1 \%$ pretreated rye straw, soya-casein agar and Mueller Hinton agar.

\section{Experimental design of cellulolytic assays}

Fresh nutrient media were prepared before each experiment and used for growing of mesophilic and thermophilic bacterial populations. The prepared media were sterile pipetted in $10 \mathrm{ml}$ glass tubes, inoculated with bacterial consortium and cultivated at anaerobic conditions. The tubes were preliminary reduced for $24 \mathrm{~h}$ and purged with a gas mixture of $80 \% \mathrm{~N}_{2}$ and $20 \% \mathrm{CO}_{2}$. Anaerobic conditions were prepared in jars by gasgenerating GasPakTM EZ bags for anaerobic container system (Becton Dickinson, 260678) and were controlled by indicators (Merck, 1.15112.0001).

Determination of the degree of filter paper and medical gauze degradation by anaerobic mesophilic and thermophilic bacterial communities

Bacterial inoculums were taken from mesophilic and thermophilic anaerobic bioreactors (BR1 resp. BR2) and were inoculated into glass tubes loaded with filter paper strip (resp. medical gauze) and culture medium. After day 15 of the beginning of the experiment, the results were visualized (Figure 2). The residual amount of cellulose in the glass tubes loaded with filter paper (resp. medical gauze) was determined spectrophotometrically by anthrone reagent at different intervals according to Updegraff's method [Updegraff, 1969]. The acetic-nitric reagent removes all substances except cellulose. After centrifugation of $10 \mathrm{ml}$ sample at $2500 \mathrm{rpm}$ for 5 min the supernatant was removed and $5 \mathrm{ml} 67 \%$ $\mathrm{H}_{2} \mathrm{SO}_{4}$ was added to the precipitate and incubated for $60 \mathrm{~min}$ at room temperature. Afterwards the samples were diluted 50 times with $\mathrm{dH}_{2} \mathrm{O}(0.1 \mathrm{ml}$

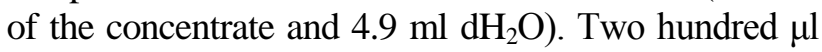
of the diluted solution in combination with $0.8 \mathrm{ml}$ $\mathrm{dH}_{2} \mathrm{O}$ and $2 \mathrm{ml}$ anthrone reagent were used for the experiment. The extinction of the sample was measured at $620 \mathrm{~nm}$. 
Determination the potential of bacterial mesophilic and thermophilic communities to degrade vegetable residues

From the $3^{\text {rd }}$ passage of the mesophilic and $2^{\text {nd }}$ passage of the thermophilic bacterial population, it was prepared new ones by inoculating in $50 \mathrm{ml} 520$ and $122 \mathrm{DSMZ}$ nutrient media loaded with $1 \mathrm{~g}$ vegetable mixture (shredded peppers, cucumbers, carrots and potatoes), respectively $4^{\text {th }}$ and $3^{\text {th }}$ passages. To perform gravimetric analysis, we used the protocol of Tailliez et al. (1989). Briefly, portions of the bacterial culture medium were centrifuged at $5000 \times \mathrm{g}$ for $15 \mathrm{~min}$. The pellet was suspended in $3 \mathrm{ml}$ of acetic-nitric reagent by Crampton and Maynard and heated at $100^{\circ} \mathrm{C}$ for $30 \mathrm{~min}$ to achieve cell lysis. The residual cellulose was washed with water, centrifuged and the precipitate was dried for 3 days at $60^{\circ} \mathrm{C}$.

\section{Assessment of volatile fatty acides concentration}

Volatile fatty acids concentrations were measured by gas chromatograph "Focus GC" (Thermo Scientific) equipped with a Split/Splitless injector, TG-WAXMS (Length -30 m., ID - 0.25 $\mathrm{mm}$, film - $0.25 \mu \mathrm{m}$ ) column and FID.

\section{Statistics}

Results are expressed as means \pm standard deviation (SD). The difference between two means was compared by a two-tailed unpaired Student's test. $\mathrm{P}$ values of $<0.05$ were considered as significant.

\section{RESULTS}

The comparison of biodegradation rates of different cellulose substrates at mesophilic and thermophilic anaerobic conditions showed that both bacterial communities have cellulolytic capacity. Their specific parameters depend on the temperature shifts and the time of interaction.

\section{Determination of cellulose biodegradation of medicinal gauze under mesophilic and thermophilic anaerobic conditions}

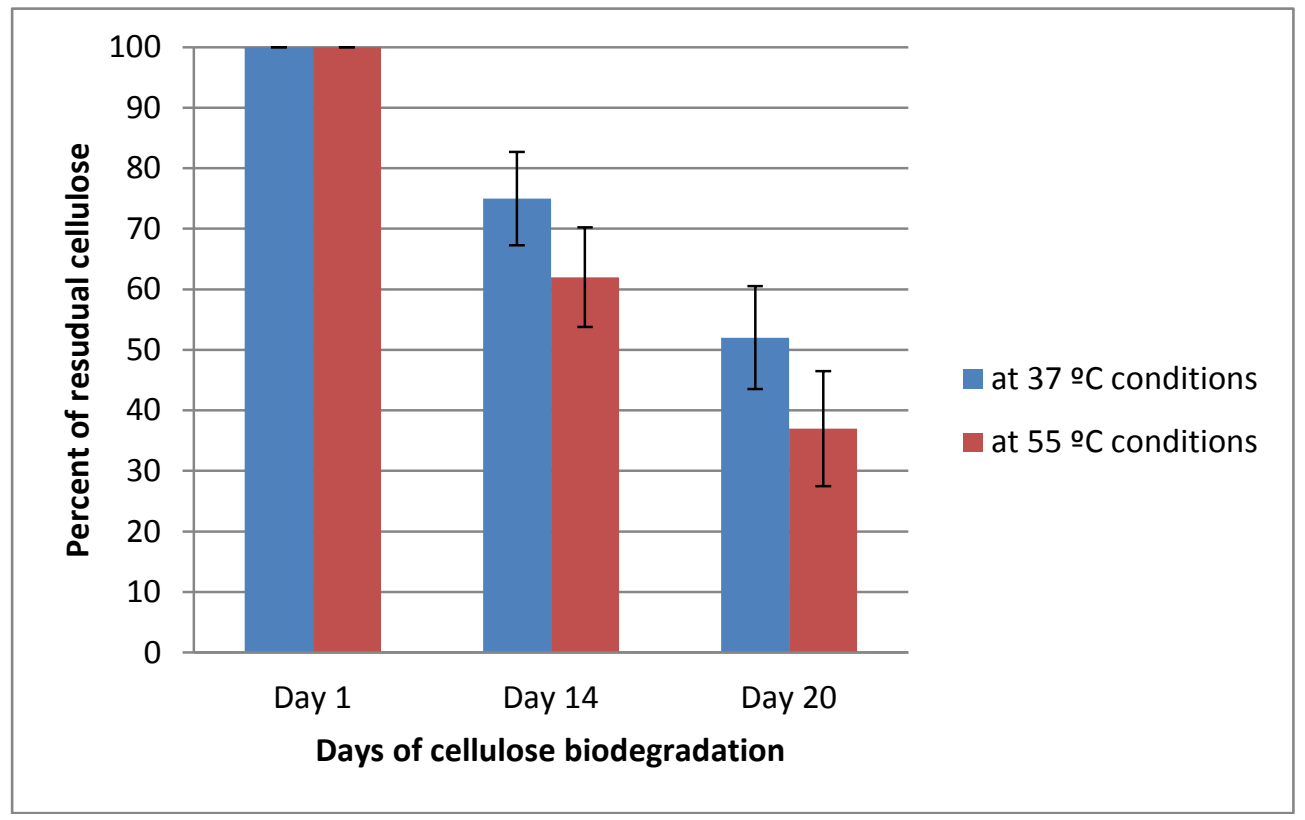

Figure 2. Comparative analysis of the percentage of residual cellulose after anaerobic degradation of medical gauze by mesophilic and thermophilic bacterial communities

The analysis shows that on the 14th day at $55^{\circ} \mathrm{C}$ the cellulose biodegradation precedes faster $(38 \%)$ than the tubes cultured at $37^{\circ} \mathrm{C}(25 \%)$. At day 20 thermophiles decomposed the medicinal gauze with about $63 \%$ in comparison with mesophiles, which degradated the same gauze with $48 \%$. Despite the observed tendency for higher cellulolytic activity of the thermophilic microbial population, the results obtained are not statistically significant $(\mathrm{P}>0.05)$. 


\section{Determination of residual cellulose from biodegradation of filter paper under mesophilic and thermophilic anaerobic conditions}

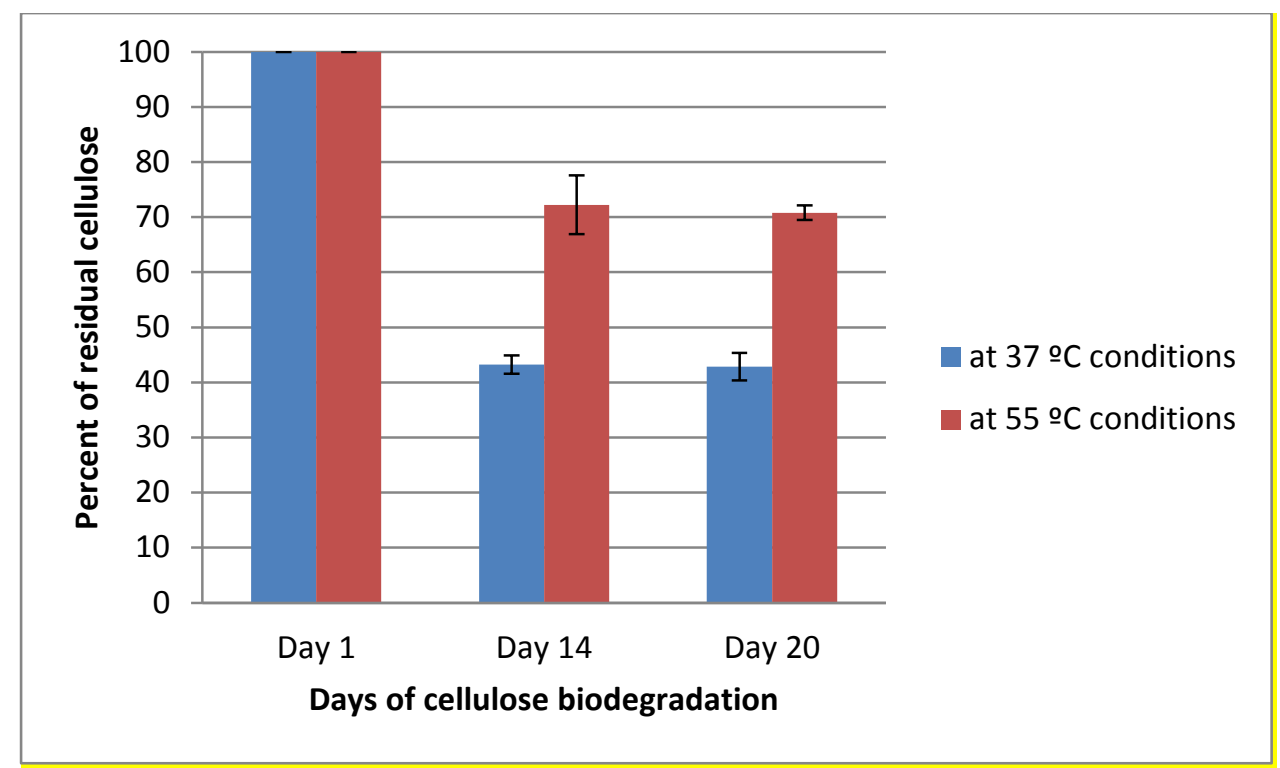

Figure 3. Comparative analysis of the percentage of residual cellulose after anaerobic degradation of filter paper by mesophilic and thermophilic bacterial communities

Determination of the potential of bacterial

In the comparative analysis, no significant difference was found in the residual amount of cellulose in the samples cultivated at mesophilic conditions between the $14^{\text {th }}$ and $21^{\text {st }}$ days. On the $14^{\text {th }}$ day, the mesophilic bacterial population from BR1 decomposed the filter paper more intensively (about 57\%) than the thermophilic bacteria (about 28\%). mesophilic and thermophilic communities to degrade vegetable residues

After several pre-passaging of bacterial inoculums $-4^{\text {th }}$ for mesophilic bioreactor (BR1) and $3^{\text {th }}$ from the thermophilic bioreactor (BR2) we compared their potential to decompose cellulose substrates available in vegetable mixture of peppers, cucumbers, carrots and potatoes in equal weights.

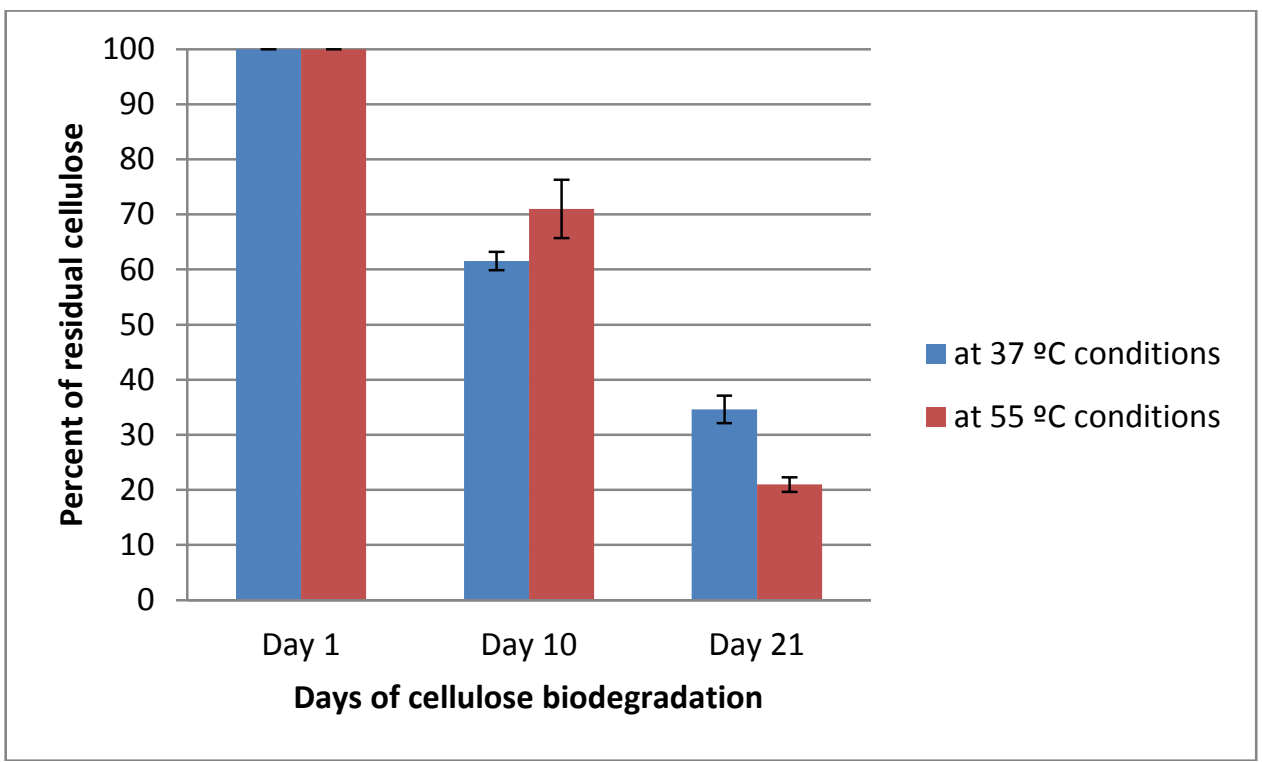

Figure 4. Comparative gravimetric analysis of the percentage of residual cellulose after anaerobic degradation of vegetable mixture by mesophilic and thermophilic bacterial communities 
It was found that on the $10^{\text {th }}$ day the biodegradation of cellulose was $38 \%$, while on the $21^{\text {st }}$ day it reached to $65 \%$ after cultivation at $37^{\circ} \mathrm{C}$. Correspondingly at $55^{\circ} \mathrm{C}$ of cultivation (thermophilic conditions), 10 days after incubation the biodegradation of cellulose was $29 \%$, while on the $21^{\text {st }}$ day it was $79 \%$.
Determination of the profile and dynamics of volatile fatty acids during anaerobic cellulose biodegradation

The profile of volatile fatty acids formed during the degradation of filter paper by the mesophilic bacterial population was determined, as a major metabolic product in the process. The concentrations of volatile fatty acids were measured with a Focus GC gas chromatograph. The results are presented in Table 1.

Table 1. The amount of volatile fatty acids formed during the cellulose biodegradation process

\begin{tabular}{|c|c|c|c|c|c|c|c|}
\hline \multirow{2}{*}{$\begin{array}{c}\text { Cultivation } \\
\text { (days) }\end{array}$} & \multicolumn{7}{|c|}{ Volatile fatty acids (g/L) } \\
\cline { 2 - 8 } & acetate & propionate & isobutyrate & butyrate & isovalerate & valerate & caproate \\
\hline 7 & 1.26 & 0.09 & 0.03 & 0.1 & 0.04 & 0.00 & 0.00 \\
\hline 17 & 1.79 & 0.08 & 0.03 & 0.14 & 0.04 & 0.00 & 0.00 \\
\hline 22 & 2.45 & 0.26 & 0.06 & 0.33 & 0.06 & 0.00 & 0.00 \\
\hline
\end{tabular}

As could be seen, the percentage of the released acetate is highest, followed by butyrate and propionate. Starting from 1.26 on the seventh day of cultivation, it almost doubles to 21 days going to
$2.45 \mathrm{~g} / \mathrm{L}$. The same trend is observed for the propionate and especially for butyrate, which is increased 3 times. No evidence for releasing of valerate and caproate was found.

\section{Light microscopy of isolated mesophilic anaerobic bacterial consortia}

The microscopic preparations by Gram staining from the effectiveness bacterial mesophilic

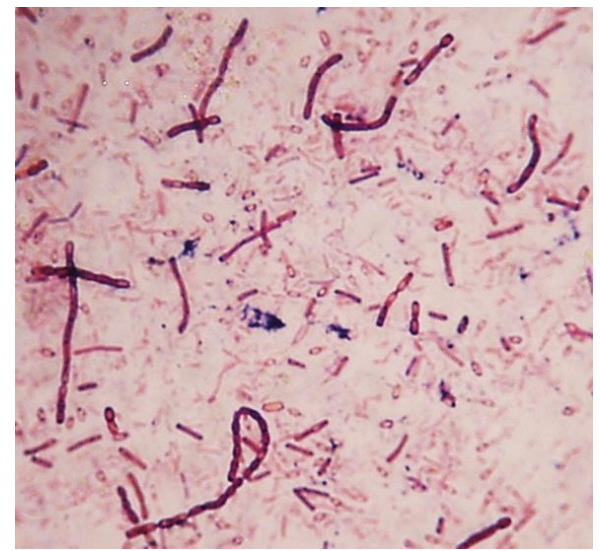

population were made and photodocumented under light microscopy (Figure 5).

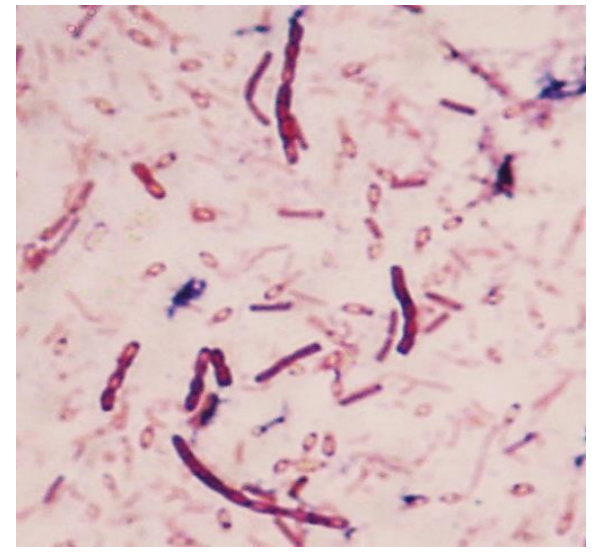

Figure 5. Microphotographs of mesophilic and thermophilic bacterial population degrading different cellulose sources $(\times 1000)($ left - microbial cells from BR1; right - microbial cells from BR2)

It was observed the presence of Gram-positive spore forming bacillary (short and long forms) and typical clostridia forms. Some of the cells are bipolar and others are in the process of division.

\section{DISCUSSION}

In nature, the cellulose, lignocellulose and lignin are major sources of plant biomass therefore their recycling is indispensable for the carbon cycle. The synergistic action of a variety of microorganisms is needed for recycling lignocellulosic materials. Lignocellulose is a term for plant materials that are composed of matrices of cellulose, hemicellulose, and lignin. The capacities of microorganisms to assimilate complex carbohydrates, such as cellulose, hemicellulose and lignin, depend on the ability to produce synergically acting enzymes. In the near future, processes that use lignocellulolytic enzymes 
and microorganisms as producers could lead to new, environmentally friendly technologies.

Long terms of the planned space expeditions require the creation of the most closed LSS of crews in spacecraft with cyclic regeneration of substances in an artificial ecosystem [Romanov et al., 2007]. One of the main conditions for increasing the closure factor of LSS is the processing of waste in order to return the maximum proportion of the elements contained in them to the circulation of substances on board of the ISS.

The involvement of various microorganisms (both bacteria and fungi) growing under mesophilic or thermophilic conditions is prerequisite for biodegradation of lignocellulose containing waste. In the last two decades, research has been focused at developing of new technologies and microbial strains reducing the cost of cellulase production and improving the bioconversion of cellulose.

In connection with future manned space flights to Mars, the problem of utilising the wastes accumulated on board the spacecraft becomes especially topical. One possibility for this issue to be solved is by using microorganisms for effective biodegradation of the wastes, which is the aim of research on the proposed project. For hygiene needs, space crews have been using chiefly napkins and towels on cellulose basis that form the greater part of the wastes. Another potential part of the wastes represent the uneatable residues of grown on board plants which are degradable easier. For the purpose, microorganisms of the genus Clostridium, can be used, in the form of monoculture or in association with other microorganisms (Rhodobacter, Rhodopseudomonas, Enterobacter, Lactobacillus). The anaerobic digestion is preferable, since the oxygen necessary for the crew is not consumed. The final product of such a process is methane which can be stored in special reservoirs or serve as a substrate of another microbiological process involving methanotrophs and be degraded to $\mathrm{CO}_{2}$ and $\mathrm{H}_{2} \mathrm{O}$ which can be used in covered-type space greenhouses. However, the latter is the goal of future research. Besides, the anaerobic processes can be realized by bacteria developing at mesophilic $\left(20-45^{\circ} \mathrm{C}\right)$ or thermophilic conditions $\left(50-70^{\circ} \mathrm{C}\right)$.

In our studies we isolated two bacterial consortia which turn to be stable with satisfactory cellulolytic activities proved on three substrates - filter paper, medical gauze and vegetable mixture. We obtained better cellulolytic activity at mesophilic degradation of filter paper at anaerobic conditions and therefore we turned our attention to mesophyles for future studies directed to development of laboratory technologic model. It is known that the thermophilic cellulolytic bacteria of the genus Clostridium are very promising for the purposes of cellulose biodegradation. In contrast, concerning the space flight conditions, maintaining of high temperature is related with higher energy consumption and it is not life supporting for astronauts in manned space flights, so it could be regarded as one of the limiting factors.

According to Zhang et al. (2017), the acetate concentration increases when the $\mathrm{pH}$ drops below 6.5 and decreases when the $\mathrm{pH}$, as well as the butyrate, increases. Therefore, a change in $\mathrm{pH}$ leads to a change in the distribution of fermentation products. There is a good correlation between the breakdown of cellulose and the increase in acetate. In our experiments, acetate ranged from $60.3 \%$ for processes that started directly with a bacterial community from methanogenic mesophilic and thermophylic bioreactors - BR1 and BR2. It could be assumed that methane formation does not take place, as the accumulation of volatile fatty acids is observed in the process of biodegradation of the filter paper, and is not absorbed and exhausted. In our case, we can assume that the breakdown of cellulose is carried out by mixed bacterial consortia through mixed acid fermentation (Zang et al., 2017). The volatile fatty acids can serve as substrates for the next step in closed microenvironmental life support systems, such as MELiSSA.

Taking into consideration that the results on cellulose biodegradation are due to synergism between the various bacterial species presented in the consortia we plan to do methagenomic analysis and to reveille the bacterial composition and even to isolated individual species with promising cellulolytic activity.

ACKNOWLEDGEMENTS: This work was supported both by the National Science Fund of Bulgaria under the Bilateral Cooperation Programs 2016 - Bulgaria-Russia (Project ДНТС/Русия 01/4/23.06.2017) and by the Russian Foundation for Basic Researches within the frame of Russian/Bulgarian Project № 17-54-18071/18.

\section{REFERENCES}

APHA, Standard methods for the examination of waste and wastewater. American Public Health Association, Washington, DC, 2005.

Benot M., D. Klaus, Can genetically modified Escherichia coli with neutral buoyancy induced by gas vesicles be used as an alternative method to clinorotation for microgravity studies? Microbiology, 2005, 151, 69-74. 
Berkovich Yu.A., Krivobok N.M., Smolyanina S.O., Erokhin A.N. Space greenhouses: the present and the future. M.: Firm "Word", 2005, pp. 92-94 (in Russian).

Bilai V.I., Biology of cellulose-destroying fungi. In: Problems of bioconversion of plant raw materials. Under. Ed. Skryabin GK, 1986., pp. 6 - 29 (in Russian).

Bouloc P., R. D'Ari, E.coli metabolism in space, J. Gen. Microbiol., 1991, 137, 2839-2843.

Chynoweth D., J. Owen, A. Teixeira, P. Pullammanappallil, S. Luniya. Anaerobic digestion of space mission wastes. Wat. Sci. Technol., 53, 8, 2006. 177-185.

Chynoweth D., R. Legrand, Apparatus and method for sequential batch anaerobic composting of highsolids organic feedstock. US Patent 5269 634, 1993.

Ilyin, V.K., D.V. Korshunov, E.A. Deshevaya. Biotransformation of used means of personal hygiene of cosmonauts and vegetable waste as applied to life support systems for space crews. Ecol. Eng. Environ. Protect., No 1, 2018, p. 5-23

Jones, H. Comparison of bioregenerative and physical-chemical life support systems. SAE Technical Paper 2006-01-2082, 2006.

Hendrickx L., H. De Wever, V. Hermans, F.Mastroleo, N. Morin, A.Wilmotte, P...Janssen, M.Mergeay. Microbial ecology of the closed artificial ecosystem MELiSSA (Micro-Ecological Life Support System Alternative): Reinventing and compartmentalizing the Earth's food and oxygen regeneration system for long-haul space exploration missions. Res. Microbiol., Vol. 157 (1) 2006, pp. 77-86

Lasseur C., J. Brunet, H. de Weever, M. Dixon, G. Dussap, F. Godia, N. Leys, M. Mergeay, D. Van Der Straeten. MELiSSA: the European project of

\section{H. Najdenski, V. Hubenov, V. Kussovski, L. Dimitrova, I. Simeonov}

The Stephan Angeloff Institute of Microbiology,

The Bulgarian Academy of Sciences

Department of Infectious Microbiology

Acad. Georgi Bonchev Str., bl. 26

1113 Sofia, Bulgaria

e-mail:hnajdenski@abv.bg

\section{P. Angelov}

Space Research and Technology Institute

The Bulgarian Academy of Sciences

Acad. Georgi Bonchev Str., bl. 1

1113 Sofia, Bulgaria

e-mail: pangelov@space.bas.bg closed Life Support System. Gravitat. Space Biol., Vol. 23 (2), 2010, 3-12

Loginova L.G., I.I. Ivanova, E.P. Guzhova, G.I. Khraptsova, D.Yu. Ismailova, L.G. Burdenko. Cellulases of thermophilic microorganisms. In: Problems of bioconversion of plant raw materials. M.: Science. 1988.S. 165-192 (in Russian).

Pullammanappallil, P., A. Dhoble. Biochemical methane potential of wastes generated during longterm lunar mission. $40^{\text {th }}$ International Conference on Environmental Systems, 11-15 July, 2010, Barcelona, Spain.

Romanov S., A. Zheleznyakov, A. Telegin etc. Life support systems for crews of long-term interplanetary expeditions, Izv. RAS. Power Engineering, 3, 2007, 57-74 (in Russian).

Schwarz, W. H. The cellulosome and cellulose degradation by anaerobic bacteria. Appl. Microbiol. Biotechnol., Vol. 56, 5-6, 2001, 634-649.

Tailliez, P., H. Girard, J. Millet, P. Beguin. Enhanced cellulose fermentation by an asprogenous and ethanol tolerant mutant of Clostridium thermocellum, Appl. Environ. Microbiol., 55, 1989, 207-211.

Taylor, G. R.; Bailey, J. V.; Benton, E. V. Physical dosimetric evaluations in the Apollo 16 microbial response experiment. Life Sci. Space Res., 13: 1975135-41.

Updegraff D. M.. Semimicro determination of cellulose in biological materials. Analytical Biochemistry, Vol. 3, 2, 1969, 420-424.

Updegraff D., Semi-micro determination of cellulose in biological materials. Analyt. Biochem., 32, 1969, 420-424.

Wang, M., K. Liu, L. Dai, J. Zhang, X. Fang. The structural and biochemical basis for cellulose biodegradation. J. Chem. Technol. Biotechnol., Vol. $88,4,2013,491-500$.

\author{
V.K. Ilyin, D.V. Korshunov \\ Russian Federation State Scientific Center- \\ Institute for Biomedical Problems (IBMP) \\ 123007 Khoroshevskoye shosse 76a \\ Moscow, Russia \\ e-mails: ilyin@imbp.ru, shinobi83@mail.ru
}

